\title{
Glucose biosensor based on entrapment of glucose oxidase and myoglobin in silica gel by the sol-gel method
}

\author{
Mohammed A. Zaitoun * \\ Chemistry Department, Mutah University, PO Box 10, Karak, Jordan \\ Tel.: +962 032372 380; Fax: +96203 2375540; E-mail: zaitoun444@yahoo.com, \\ zaitoun@mutah.edu.jo
}

\begin{abstract}
A spectrophotometric method is presented to determine glucose employing the sol-gel technique. Myoglobin (Mb) and glucose oxidase are encapsulated in a transparent and porous silica glass. The produced gel (xerogel) is then immersed in water where increments of glucose are added to the solution with stirring; glucose diffuses into the sol-gel glass pores and a series of reactions take place. Glucose is first oxidized by glucose oxidase and oxygen to gluconate and hydrogen peroxide is generated. The liberated hydrogen peroxide oxidizes the $\mathrm{Mb}$ heme $\left(\mathrm{Fe}^{2+}\right.$ into $\left.\mathrm{Fe}^{3+}\right)$. The higher is the glucose concentration added, the more is the $\mathrm{H}_{2} \mathrm{O}_{2}$ generated, and the more is the $\mathrm{Mb}$ oxidation $\left(\mathrm{Fe}^{2+}\right.$ to $\mathrm{Fe}^{3+}$ ) and as a result the higher is the absorbance at $400 \mathrm{~nm}$ (negative peak, lower absorbance value). All measurements are performed at this wavelength (400 $\mathrm{nm}$ ), the negative peak obtained by subtracting the absorption spectra of $\mathrm{Mb}$ before and after oxidation. Measuring the slope of the absorbance decay versus time at $400 \mathrm{~nm}$ monitors increments of added glucose. Each glucose concentration has an accompanying unique decay curve with a unique slope. The higher is the glucose concentration; the steeper is the decay curve (higher slope value). The calibration curve was linear up to $40 \mathrm{mM}$.
\end{abstract}

\section{Introduction}

For many years, the glucose content of blood and urine was determined in the diagnosis of diabetes, a disease in which the blood glucose level is abnormally high and there is excessive urinary excretion of glucose. Now more sensitive methods for measuring blood glucose employ the enzyme, glucose oxidase in the presence of oxygen; gluconate and hydrogen peroxide are generated in this reaction [1,2].

Clark and Lyons first introduced the concept of glucose sensor in 1962. In their article dealing with continuous monitoring of blood chemistry, they suggested that a thin layer of soluble enzyme might be retained at the surface of an oxygen electrode using a dialysis membrane [3]. Glucose and oxygen would diffuse into the enzyme layer from the sample site and the consequent depletion of oxygen would provide a measurement of the glucose concentration. The first article describing an immobilized enzyme electrode was due to Updike and Hick in 1967 [4]. They immobilize the enzyme glucose oxidase in a polyacrylamide gel at an oxygen electrode. Since this pioneer work in the 1960s, reasonable research effort has been devoted to the development of glucose sensors by a number of research groups worldwide [5-8]. Recently, glucose sensor research is a relative mature and well-worked research field [9-11].

* On Sabbatical at Salalah College of Education, PO Box 3093, Salalah 211, Oman. 
The majority of sensors is based on electrochemical principles and employs enzymes as biological components for molecular recognition. Several new techniques for glucose sensing have been developed in clinical practice [12] as well as in biotechnology [13] and food industry [14]. This has inspired the development of an analytical method that can determine trace amounts of glucose with high precision when analytical separation techniques, such as chromatography and extraction, cannot be applied. Some methods with high sensitivity and accuracy, such as the biosensor [14], chemiluminometric peroxidase sensor [15] and label glucose oxidase method [16], have been reported, they require some specific apparatus and lengthy period of analysis. Analytical techniques for the determination of glucose utilizing a glucose biosensor based on an enzymatic membrane electrode were also discussed [15,17]. However, it is difficult to evaluate and maintain the sensitivity of an enzymatic electrode. Again, these methods require a specific apparatus (reactor or host). Immobilized enzyme methods have shown flexibility and applicability to the construction of analytical systems, since an enzyme only provides a selective catalytic effort for each individual reaction [18-26].

The sol-gel involves low temperature hydrolysis of a suitable metal alkoxide precursor followed by condensation to produce colloidal particles (sol), then gelation to form a wet network of porous metal oxide, and finally drying and shrinkage to form the xerogel (air dried gel) [27,28]. The sol-gel method is a convenient way to synthesize a host matrix for inorganic, organic and biomolecules. The substance to be encapsulated (the dopant) is added to the sol after partial hydrolysis of the precursor. As the degree of cross-linking from polycondensation increases, the gel becomes viscous and solidifies. The process continues during aging and the porous matrix is formed around the dopant molecules. The addition of the dopant molecule prior to the gelation process physically traps the dopant in the cross-linked network and ensures the homogeneous distribution of the dopant [29]. The principal advantages for this process are the room temperature (or lower) processing conditions, chemical inertness, negligible swelling effects, tunable porosity, the ease with which the microstructure of the material can be modified by varying the process parameters, and high purity of sol-gel derived glasses make them ideal for many types of sensor application [30,31]. For optimum biostability and reaction efficiency, the sol-gel matrix isolates the encapsulated biomolecule, protects it from self aggregation and microbial attack, and provide essentially the same local aqueous microenvironment as in biological media [32,33].

The sol-gel process has been frequently used for enzyme immobilization in biosensors, both bulk monolith gels and thin films were reported. Braun et al. [34] reported on the preparation of a $8 \times 2 \mathrm{~mm}$ disk of tetramethyl orthosilicate (TMOS) derived xerogel doped with glucose oxidase, peroxidase, and a chromogenic dye for detection of glucose. Yamanaka et al. [35] investigated the activity of the activity of the encapsulated glucose oxidase with a photometric detection scheme. Tatsu et al. [36] prepared tetramethyl orthosilicate (TEOS) derived sol-gel monolith doped with glucose oxidase and used it as a glucose recognition element in a flow injection analytical system. Dave et al. [37] reviewed the solgel encapsulation methods for biosensors in 1994. Narang et al. [7] reported the characterization of thin sol-gel films derived from TEOS that are doped with glucose oxidase as a prototype for sol-gel based biosensor development. Chung et al. [38] encapsulated myoglobin in a TMOS monolithic glass matrix and were examined as a sensing element for measurement of dissolved oxygen. Lan et al. [39] examined a series of heme proteins including myoglobin encapsulated in monolithic TEOS gels, the trapped proteins retained their spectroscopic properties and chemical function. Jin et al. [4] reviewed the properties and applications of proteins encapsulated in sol-gel materials.

In the present work, $\mathrm{Mb}$ absorption spectra before and after oxidation by hydrogen peroxide are first generated. The difference produces a peak at $400 \mathrm{~nm}$ in the negative direction, all our measurements are recorded at this wavelength. The more $\mathrm{Mb}$ is oxidized the higher is the intensity of this peak. 
To determine glucose in a solution: $\mathrm{Mb}$ and glucose oxidase are encapsulated in an optically transparent glass via the sol-gel method; the produced xerogel is then immersed in water in a vial. The glucose concentration to be determined is added into the vial where changes in their visible absorption spectra are monitored.

Measuring the slope of the absorbance decay versus time at $400 \mathrm{~nm}$ monitors increments of added glucose. The higher is the glucose concentration added, the more is the hydrogen peroxide generated and as a result more $\mathrm{Mb}$ is oxidized and the absorbance at $400 \mathrm{~nm}$ is increased. Each glucose concentration has an accompanying unique decay curve with a unique slope.

\section{Experimental}

\subsection{Apparatus}

Electronic absorption spectra were recorded on a spectrophotometer type Specord M 500 (Zeiss, Germany). Myoglobin spectra before and after oxidation were recorded over the range 200-700 $\mathrm{nm}$. A 523 WTW (Williams Talhar and Wong International) pH meter with a WTW pH glass electrode was used for all $\mathrm{pH}$ measurements. Calibration of the $\mathrm{pH}$ meter was performed at regular intervals.

\subsection{Reagents}

Analytical grade reagents and deionized, ultra filtered water was used throughout. Mb, Glucose oxidase, and $\mathrm{D}(+)$ glucose were purchased from Sigma and were used without further purification. Tetramethyl orthosilicate (TMOS, 98\%) was purchased from Aldrich.

A solution of about $200 \mu \mathrm{M}$ of $\mathrm{Mb}$ was prepared by dissolving 8-10 mg in $2.0 \mathrm{ml}$ phosphate buffer $(\mathrm{pH}=6)$. Glucose oxidase solution was prepared by dissolving about $14 \mathrm{mg}$ in $2.0 \mathrm{ml}$ phosphate buffer $(\mathrm{pH}=6)$. A 100-ppm stock solution of glucose was prepared; the remaining solutions were prepared by appropriate dilutions of the standard. Finally, a stock $4.93 \mathrm{mM}$ of hydrogen peroxide was prepared.

\subsection{Procedure}

The base line for all the absorption spectra was generated using $2.0 \mathrm{ml}$ of phosphate buffer ( $\mathrm{pH} 6$ ). The absorption spectrum of $\mathrm{Mb}$ over the range 200-700 nm was constructed by mixing $2.0 \mathrm{ml}$ buffer and $0.2 \mathrm{ml}$ of $200 \mu \mathrm{M} \mathrm{Mb}$. The ferric Mb absorption spectra over the range 200-700 $\mathrm{nm}$ was performed by mixing $2.0 \mathrm{ml}$ phosphate buffer (pH 6), $0.2 \mathrm{ml}$ of $200 \mu \mathrm{M} \mathrm{Mb}$, and $0.1 \mathrm{ml}$ of $4.96 \mathrm{mM}$ hydrogen peroxide.

The encapsulation of $\mathrm{Mb}$ and glucose oxidase in sol-gel glass was performed according to the following procedure: $1 \mathrm{ml}$ of $\mathrm{Mb}$ and glucose oxidase was mixed with TMOS (1 ml) containing $0.5 \%$ polydimethylsiloxane (molecular weight: 162, Aldrich). The reaction mixture was gently shaken until mixture became homogeneous, and allowed to gel at room temperature. The gels were air-dried for two week at ambient temperature. The produced xerogels were $2 \mathrm{~mm}$ thick and $8 \mathrm{~mm}$ in diameter.

Glucose was determined according to the following procedure: the transparent glassy xerogel containing $\mathrm{Mb}$ and glucose oxidase was placed in the optical path of a spectrophotometer in a vial containing $6 \mathrm{ml}$ water. At time 0 , a concentrated solution of glucose was added, bringing glucose concentration to $10 \mathrm{mM}$. Enzymatic oxidation of glucose produced $\mathrm{H}_{2} \mathrm{O}_{2}$, which oxidizes the $\mathrm{Mb}$ heme $\left(\mathrm{Fe}^{2+}\right.$ into $\mathrm{Fe}^{3+}$ ) and thus the absorbance decay at $400 \mathrm{~nm}$ was recorded. New glucose concentrations of 20, 40, 
and $80 \mathrm{mM}$ were added at 350,550 and 750 seconds. The experiment was repeated five times employing five aged ( 3 weeks old) gels.

\section{Results and discussion}

The current method to detect and determine glucose spectrophotometrically takes advantage of three things, (a) sol-gel materials provide excellent optical hosts for a variety of applications. The materials are made on the bench top at room temperature from solutions. They are transparent from the near UV to the near-IR regions of the spectrum. The micro porosity enables small molecules to penetrate to the interior of the solid monoliths while large molecules are physically trapped in the matrix. These materials are under active investigation for a very wide range of applications ranging from tunable solid sate lasers to biosensors $[4,40]$. The mild processing temperatures are an important advantage of the sol-gel method of making silicate optical materials, especially where they need to be integrated with other components that cannot withstand elevated temperatures [41], (b) the ability of glucose to oxidize to gluconate in the presence of glucose oxidase and oxygen, this reaction also releases hydrogen peroxide; (c) the heme group present in $\mathrm{Mb}$ which consists of a simple organic ring structure, protoporphyrin, to which is bound an iron atom in its ferrous $\left(\mathrm{Fe}^{2+}\right)$ state, and (d) the ability of $\mathrm{Mb}$ to oxidize to the ferric state by hydrogen peroxide, when the absorption spectra of $\mathrm{Mb}$ before and after oxidation are subtracted, a negative peak at $400 \mathrm{~nm}$ is produced, all kinetic measurements are studied by measuring absorbance versus time at this wavelength. The overall series of reaction that take place in the glass are:

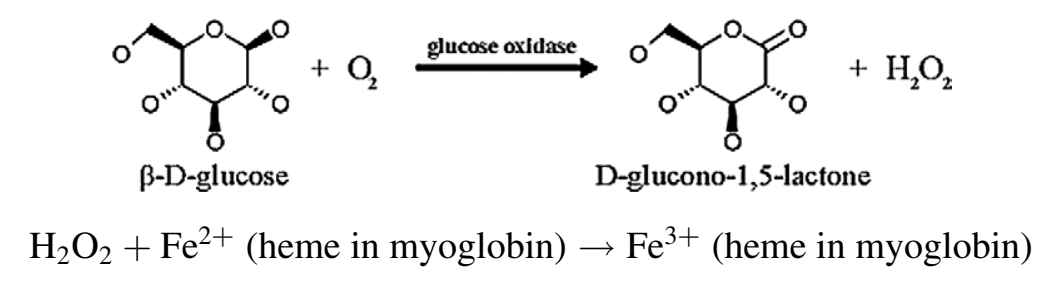

The gel containing $\mathrm{Mb}$ and glucose oxidase was porous and transparent; we did not observe any aggregation during xerogel preparations even at concentrations up to $20 \mathrm{mg} / \mathrm{g}$ glass [42]. Repeated hydration and drying of glasses resulted in fractures in large (1-2 cm in diameter) blocks. Xerogels prepared with addition of polydimethylsiloxane resulted in improved stability of glasses to cycles of drying and hydration.

Figure 1, displays the spectral changes of Mb before (Fig. 1a) and after (Fig. 1b) hydrogen peroxide is added. Clearly the Mb soret band is red shifted in Fig. 1b compared to that in Fig. 1a [25]. Figure 1c is obtained by taking the difference of Figs $1 \mathrm{a}$ and $1 \mathrm{~b}$. The $400 \mathrm{~nm}$ peak displayed in Fig. 1c is the peak we selected for measurements of absorption and kinetic studies.

Figure 2 shows the sol-gel glass at work as a glucose sensor. After each addition of glucose to the xerogel, absorbance at $400 \mathrm{~nm}$ is recorded versus time; the line slopes were calculated and are posted on the graph. The graph shows that the higher is the glucose concentration added, the higher is the slope. These data suggested that the slope, i.e., the rate of absorbance change, might be correlated with the glucose concentration added. Such an approach would have the advantage that the slope could be determined within a few minutes, which will be a critical requirement for the practical application of $\mathrm{Mb} /$ glucose oxidase gels as sensing elements. 


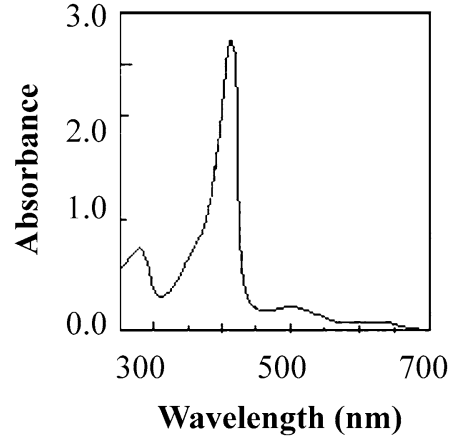

(a)

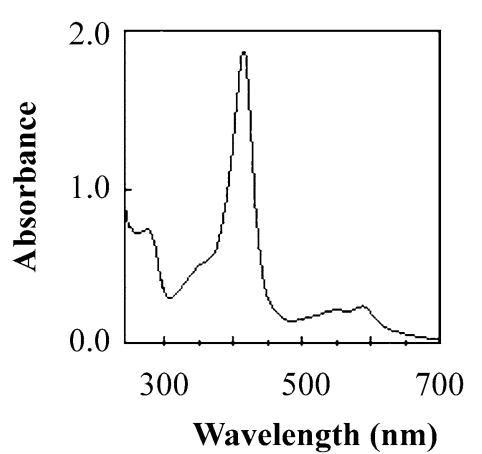

(b)

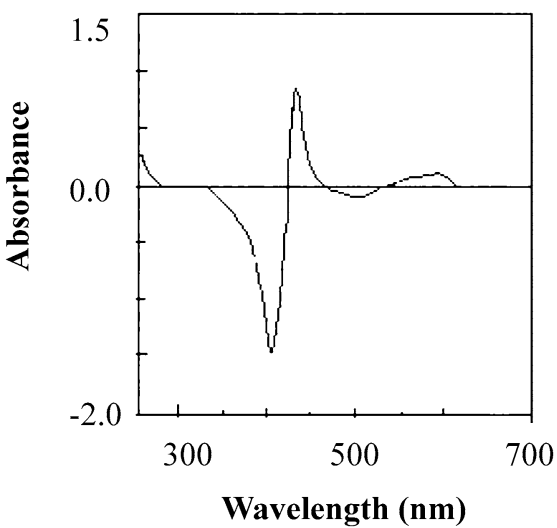

(c)

Fig. 1. Spectral changes of $\mathrm{Mb}$ before and after oxidation. (a) $2.0 \mathrm{ml}$ buffer $\mathrm{pH} 6$ and $0.2 \mathrm{ml}$ of $200 \mu \mathrm{M} \mathrm{Mb}$; (b) $2.0 \mathrm{ml}$ phosphate buffer $\mathrm{pH}$ 6, $0.2 \mathrm{ml}$ of $200 \mu \mathrm{M} \mathrm{Mb}$, and $0.1 \mathrm{ml}$ of $4.96 \mathrm{mM}$ hydrogen peroxide; (c) The difference between Figs 1a and $1 \mathrm{~b}$.

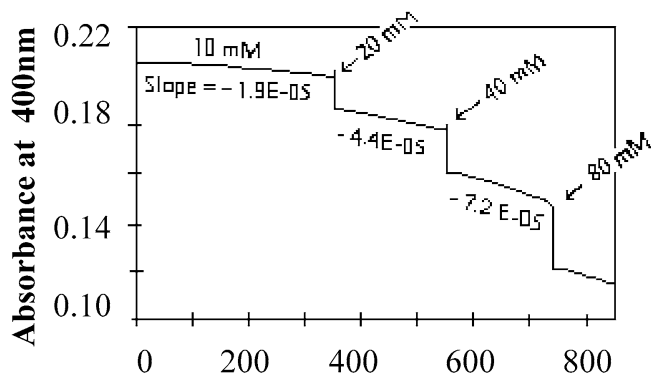

Time (sec.)

Fig. 2. Sol-gel optical glucose sensor, Xerogel $(8 \times 2 \mathrm{~mm})$ containing $\mathrm{Mb}$ and glucose oxidase was placed in the optical pathway of a spectrophotometer in a vial containing $6 \mathrm{ml}$ water. At time 0 , a concentrated solution of glucose was added, bringing glucose concentration to $10 \mathrm{mM}$. Enzymatic oxidation of glucose produced $\mathrm{H}_{2} \mathrm{O}_{2}$, which oxidizes $\mathrm{Mb}\left(\mathrm{Fe}^{2+}\right)$ into $\mathrm{Fe}^{3+}$. Absorbance decay curve versus time measured at $400 \mathrm{~nm}$ is recorded; slope for the curve is given underneath the decay line. New glucose concentrations of 20,40 , and $80 \mathrm{mM}$ were added at 350,550 , and 750 seconds.

The calibration curve was constructed by plotting (a) decay slope (rate of absorbance change) at $400 \mathrm{~nm}$ versus concentration, a correlation coefficient of 0.975412 was obtained (Fig. 3); and (b) absorbance values at $400 \mathrm{~nm}$ measured 200 seconds after each addition of glucose versus concentration, the correlation coefficient was 0.992708 (Fig. 4). Each data point in Figs 3 and 4 represent the average value of five determinations, moreover, both figures show that the response is linear up to $40 \mathrm{mM}$.

These correlation data reveal that the rate of absorbance change is directly related to the glucose concentration. The correlation is apparently unique to the glass encapsulated Mb/glucose oxidase. The rate of absorbance change depends on the transport of glucose through the porous network of the gel matrix. The absorbance change rate represent the transport rate of glucose, the rate at which $\mathrm{H}_{2} \mathrm{O}_{2}$ is generated by oxidation of glucose by glucose oxidase, and the rate at which $\mathrm{Mb}$ iron is oxidized. The transport rate of glucose is expected to be rate limiting since glucose and $\mathrm{Mb}$ oxidize rapidly by glucose oxidase and $\mathrm{H}_{2} \mathrm{O}_{2}$, respectively [18-26]. 


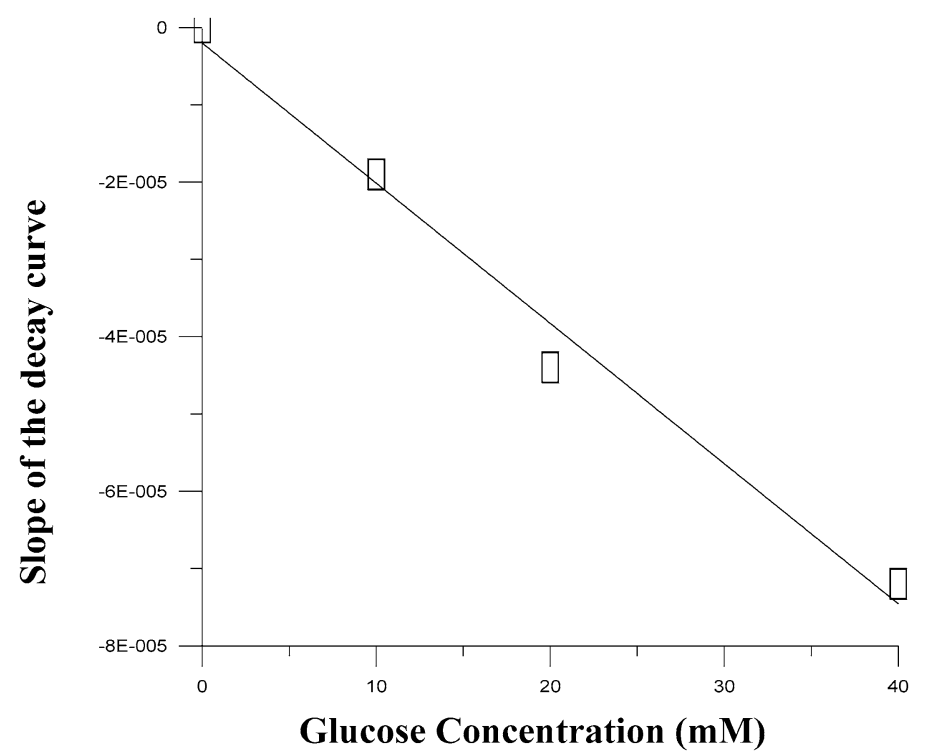

Fig. 3. Plot of slopes of the decay curves (rate of absorbance change) versus glucose concentration.

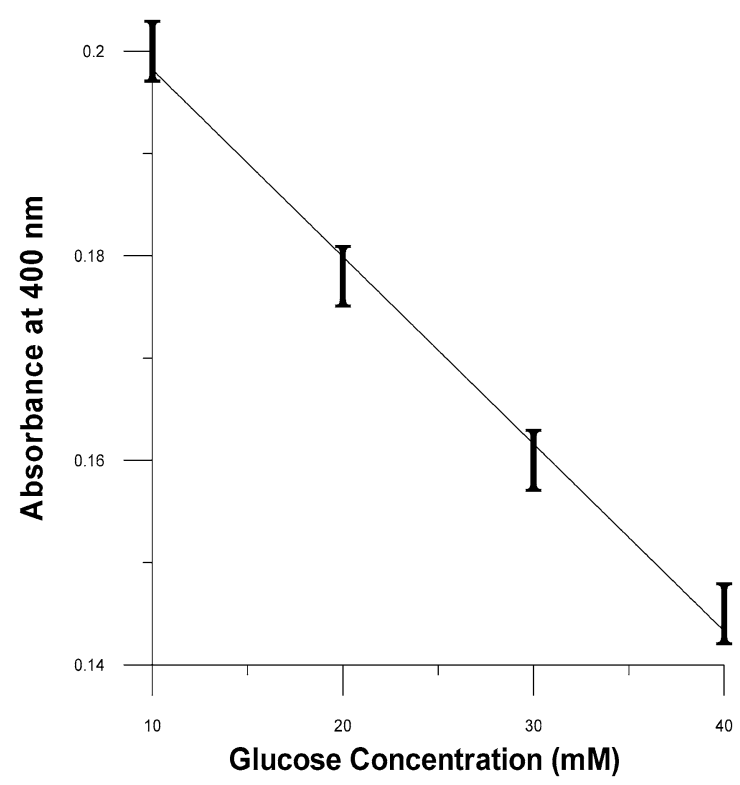

Fig. 4. Absorbance at $400 \mathrm{~nm}$ recorded 200 seconds after each addition of glucose versus glucose concentration.

The good correlation obtained in Figs 3 and 4 reveals not only that $\mathrm{Mb}$ and glucose oxidase are homogeneously distributed, but also that the pore structure is uniform throughout the glass gel. The experimental data demonstrate that the rate of absorbance change in sol-gel is directly proportional to the concentration of glucose.

We did not notice any denaturation or aggregation of Mb/glucose oxidase in sol-gel glass even for three months old gels [43]. We have found that $\mathrm{Mb} /$ glucose oxidase gels prepared and stored under identical conditions give the same kinetic behavior when exposed to glucose. 
After Mb/glucose oxidase gels are exposed to glucose, the iron is converted into $\mathrm{Fe}^{3+}$, but could be reconverted to the $\mathrm{Fe}^{2+}$ gel if it is to be reused. The regeneration of used gels could be accomplished by treatment with dithionite solution, which in this case reduces $\mathrm{Mb}\left(\mathrm{Fe}^{3+}\right)$ into $\mathrm{Mb}\left(\mathrm{Fe}^{2+}\right)$ gels. It is likely that other chemical reduction methods can be found as well. Thus, the used gels may be chemically reduced and reused for subsequent determinations.

\section{Conclusion}

Sol-gel glass encapsulated $\mathrm{Mb}$ and glucose oxidase in a monolithic gel derived from TMOS/polydimethyl siloxane has characteristics that make it an excellent sensor for glucose is reported here for the first time. These properties arise from a combination of the ability of heme-Mb to oxidize from the $\mathrm{Fe}^{2+}$ to the $\mathrm{Fe}^{3+}$ state by the hydrogen peroxide generated in the gel by the oxidation of glucose by glucose oxidase; and the optical transparency of the sol-gel matrix. The Mb/glucose oxidase encapsulated gels have been shown to exhibit three characteristics for a practical sensing element for glucose detection: (1) an optical response that is sensitive to glucose concentration; (2) an optical response that is established in few minutes; (3) relatively simple analytical equipment and procedures. The kinetics of $\mathrm{Mb}$ oxidation demonstrates that the device was glucose sensitive in the range between 0 and $40 \mathrm{mM}$, thus the encapsulated $\mathrm{Mb} /$ glucose oxidase sol-gel method has high potential as a new method for accurate and reproducible determination of glucose.

\section{References}

[1] W. Pigman and D. Horton, eds, The Carbohydrates: Chemistry and Biochemistry, Vols IA, IB, IIA and IIIB, Academic Press, New York, 1970, 1972, 1980.

[2] A.L. Lehninger, D.L. Nelson and M.M. Cox, Principles of Biochemistry, 2nd edn, Worth Publisher, New York, 1993.

[3] L.C. Clark and C. Lyons, Ann. NY Acad. Sci. 102 (1962), 29.

[4] S.J. Updike and J.P. Hicks, Nature 214(92) (1967), 986.

[5] E. Wilkins and P. Atanasov, Med. Eng. Phys. 18(4) (1996), 273.

[6] A.P. Turner and J.C. Pickup, Biosensors 1(1) (1985), 85.

[7] U. Fischer, Diabet Med. 8(4) (1991), 309.

[8] J. Jaremko, Rorstad, Diabetes Care 21(3) (1998), 444.

[9] L. Tolosa, I. Gryczynski, L.R. Eichhorn, J.D. Dattelbaum, F. Castellano, R. Govind and J.R. Lackwicz, Analytical Biochemistry 267 (1999), 114.

[10] R.M. de Laorimier, J.J. Smith, M.A. Dwer, L.L. Looger, M. Salik, C.D. Pavola, S.S. Rizk, S. Sadigov, D.W. Convad, L. Lowew and H.W. Hellinga, Protein Sci. 11(11) (2002), 2655.

[11] H.V. Hseih, Z.A. Pfeiffer, T.T. Amiss, D.B. Sherman and J.B. Pitner, Biosensors \& Bioelectronics 19(7) (2004), 653.

[12] J.C. Pickup, Lancet 2 (1985), 817.

[13] S.L. Brooks, Enzyme Microb. Technol. 13(12) (1991), 946.

[14] I. Karube and M. Tiame, Food Biotechnology 1 (1987), 147.

[15] S. Milardovic, I. Fruhak, D. Ivekovic, V. Rumenjak, M. Tkalcek and B.S. Grabaric, Anal. Chim. Acta 350 (1997), 91.

[16] N. Kiba, A. Itagaki, S. Fukumura, K. Saegusa and M. Furusawa, Anal. Chem. Acta 345 (1997), 205.

[17] J.F. Sierra, J. Galban, S. de Marcos and J.R. Castillo, Anal. Chem. Acta 368 (1989), 97.

[18] G.P. Avila, A. Salvador and M. de la Guardia, Analyst 123 (1998), 999.

[19] H. Ukeda, M. Ohira and M. Sawamura, Anal. Sci. 15 (1999), 447.

[20] M. Abraham, J. Nemcsok and B. Szujani, Intern. J. Ana. Chem. 50 (1992), 53.

[21] L. Gorton and L. Ogren, Anal. Chim. Acta 130 (1981), 45.

[22] I.L. Mattos, J.M. Fernandez-Romero, Luque De Castro and Valcarcel, Analyst 120 (1995), 179.

[23] H. Ukeda, M. Ohira and M. Sawamura, Anal. Sci. 15 (1999), 447.

[24] G.P. Avila, A. Salvador and M. de la Guardia, Analyst 123 (1998), 999.

[25] T. Taniai, A. Sakuragawa and T. Okutani, Anal. Sci. 16 (2000), 517. 
[26] T. Matsui, S. Ozaki, E. Liong and N.J. Phillips, J. Biolo. Chem. 244(5) (1999), 2838.

[27] C.J. Brinker and G.W. Scherer, Sol-Gel Science, Academic Press, San Diego, 1990.

[28] B.C. Dave, B. Dunn, J.S. Valentine and J.I. Zink, Anal. Chem. 66 (1994), 1120A.

[29] L.C. Klein, Sol-Gel Optics - Processing and Applications, Kluwer Academic, Boston, 1994.

[30] W. Jin and J.D. Brennan, Anal. Chim. Acta 461 (2002), 1.

[31] B.D. MacCraith, C.M. McDonagh, G. Okeeffe, A.K. McEvoy, T. Butler and F.R. Sheridan, Sens. Act. B 29 (1995), 51.

[32] C. Rottman, M. Ottolenghi, R. Zusman, O. Lev, M. Smith, G. Gong, M.L. Kagan and D. Avnir, Materials Lett. 13 (1992), 293.

[33] U. Narang, P.N. Prasad, F.V. Bright, K. Ramanathan, N.D. Kumar, B.D. Malhorta, M.N. Kamalasana and S. Chandra, Anal. Chem. 66 (1994), 3139.

[34] S. Braun, S. Rappoport, R. Zusman, D. Avnir and M. Ottolenghi, Mater. Lett. 10 (1990), 1.

[35] S.A. Yamanaka, F. Nishida, L.M. Ellerby, C.R. Nishida, B.J. Dune, J.S. Valentine and J.I. Zink, Chem. Mater. 4 (1992), 495.

[36] Y. Tatsu, K. Yamashita, M. Yamaguchi, S. Yamamura, H. Yamamoto and S. Yoshikawa, Chem. Lett. (1992), 1615.

[37] B.C. Dave, B. Dune, J.S. Valentine and J.I. Zink, Anal. Chem. 66 (1994), 1120A.

[38] K.E. Chung, E.H. Lan, M.S. Davidson, B.S. Dunn, J.S. Valentine and J.I. Zink, Anal. Chem. 67 (1995), 1505.

[39] E.H. Lan, B. Dave, J.M. Fukuto, B. Dunn, J.I. Zink and J.S. Valentine, Chem. Mater. 9 (1999), 45.

[40] D.C. Lia, B. Dunn and J.I. Zink, Inorg. Chem. 35 (1996), 2152.

[41] D. Avnir, S. Braun, O. Lev, Ottolenghi, Chem. Mater. 6 (1994), 1605.

[42] S. Shtelzer, S. Rappoport, D. Avnir, M. Ottolenghi and S. Braun, Biotechnol. Appl. Biochem. 15 (1992), 227.

[43] B.J. Dunn, J.S. Valantine, J.I. Zink, L.M. Ellerby, F. Nishida, C.R. Nishida and S.A. Yamanaka, U.S. patent 5,200,334, 1993. 


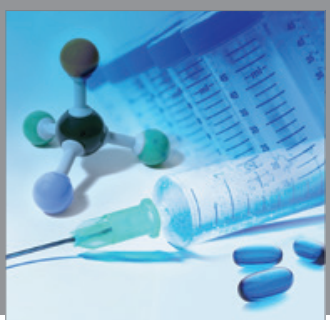

International Journal of

Medicinal Chemistry

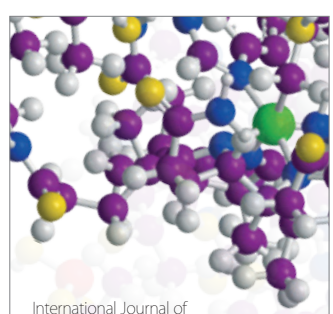

Carbohydrate Chemistry

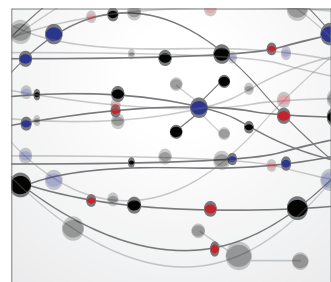

The Scientific World Journal
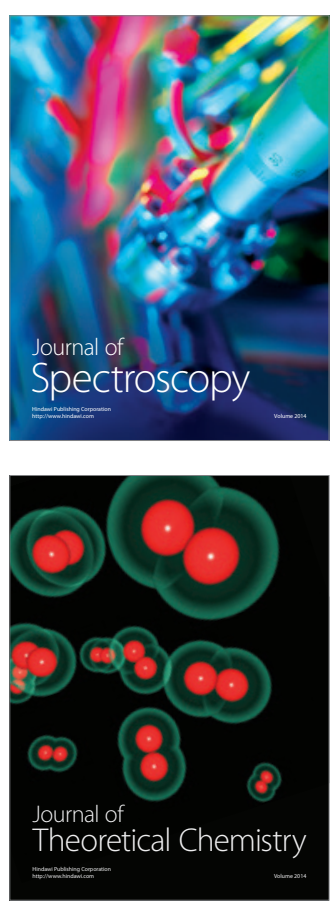
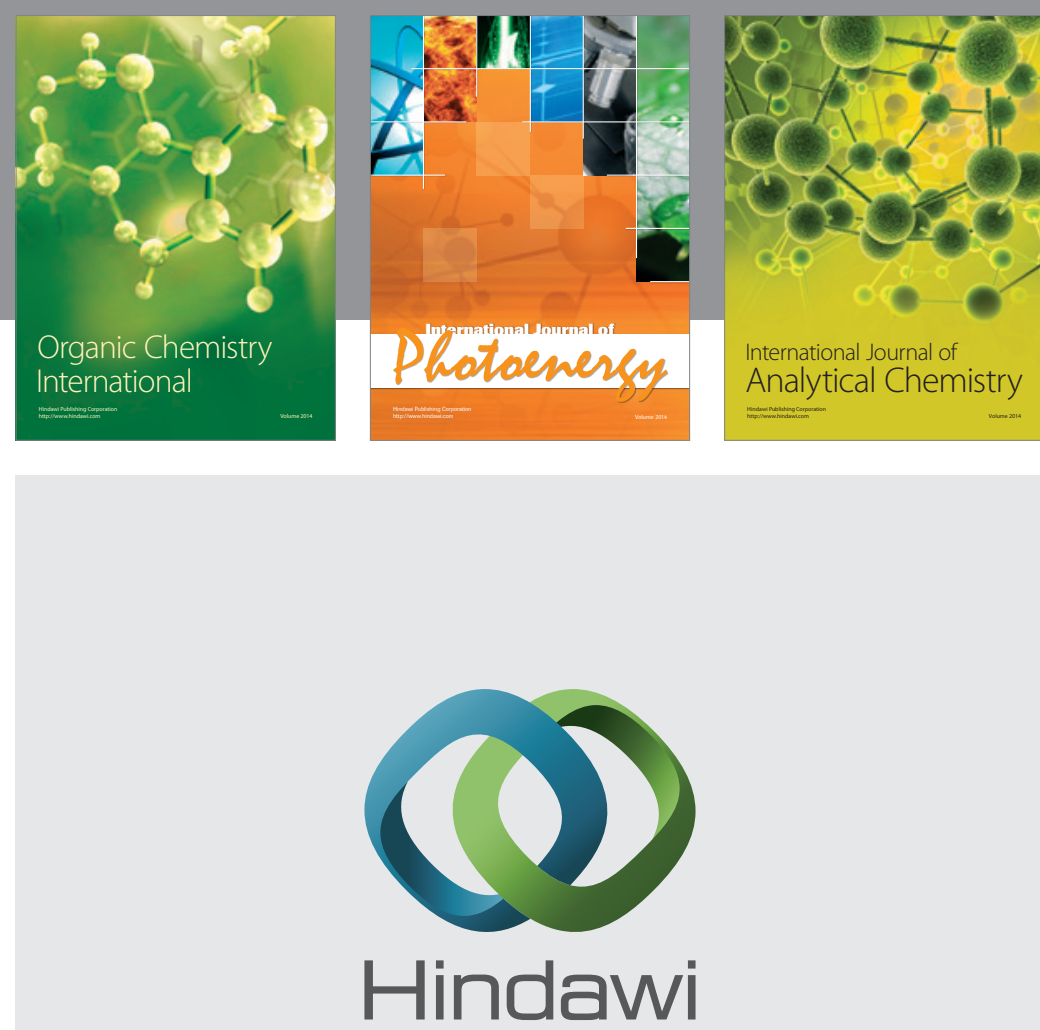

Submit your manuscripts at

http://www.hindawi.com
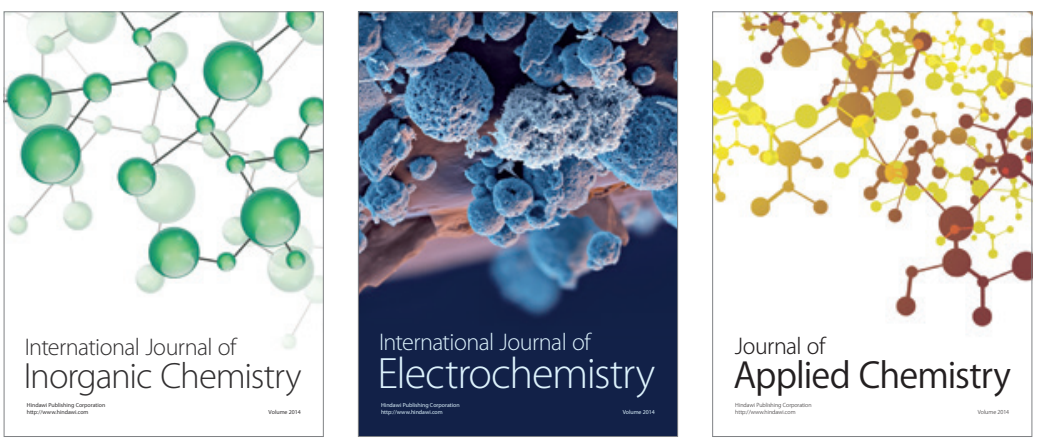

Journal of

Applied Chemistry
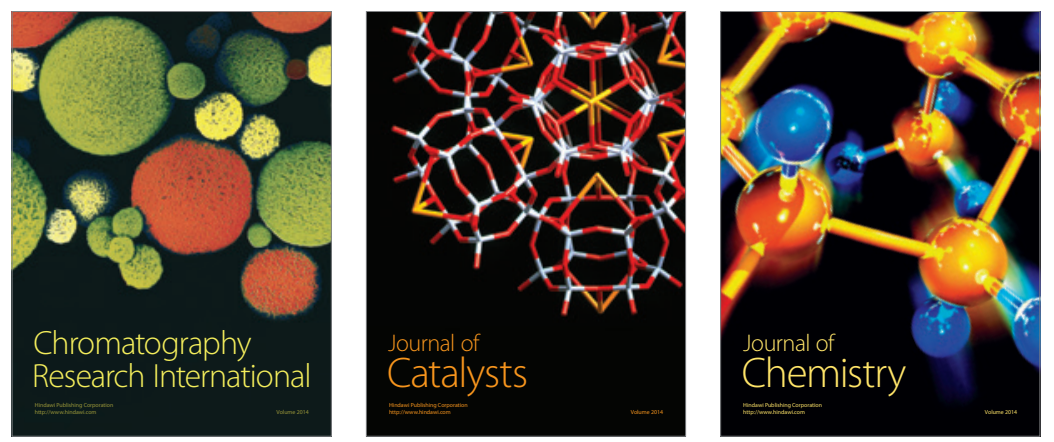
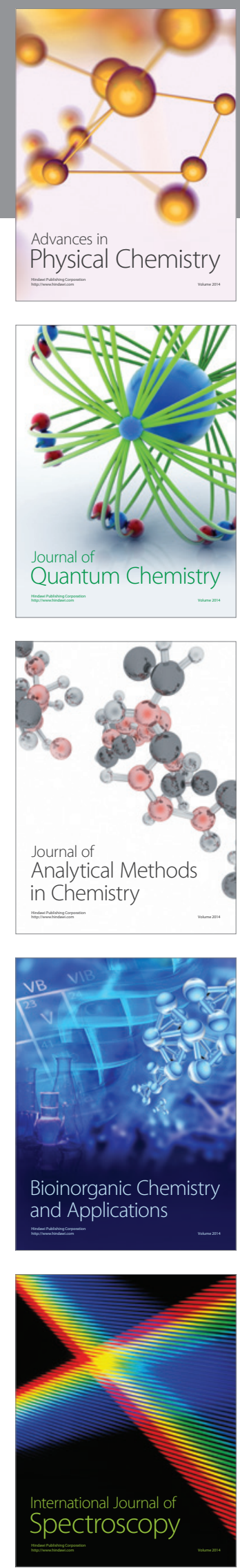